\title{
SUPPLEMENTARY INFORMATION The Dominant Role of Heterojunctions in Gas Sensing with Composite Materials
}

Anna Staerz ${ }^{a}$, Xing Gao $^{b}$, Faruk Cetmi $^{a}$, Zhang Ming ${ }^{b}$, Udo Weimar ${ }^{a}$, Tong Zhang ${ }^{b}$, and Nicolae Barsan $a^{*}$

anstitute of Physical and Theoretical Chemistry (IPTC), University of Tuebingen, Auf der Morgenstelle 15, D-72076, Tuebingen, Germany

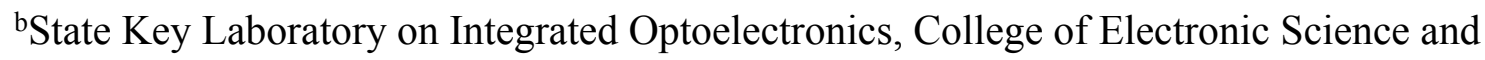
Engineering, Jilin University, Changchun 130012, People's Republic of China;

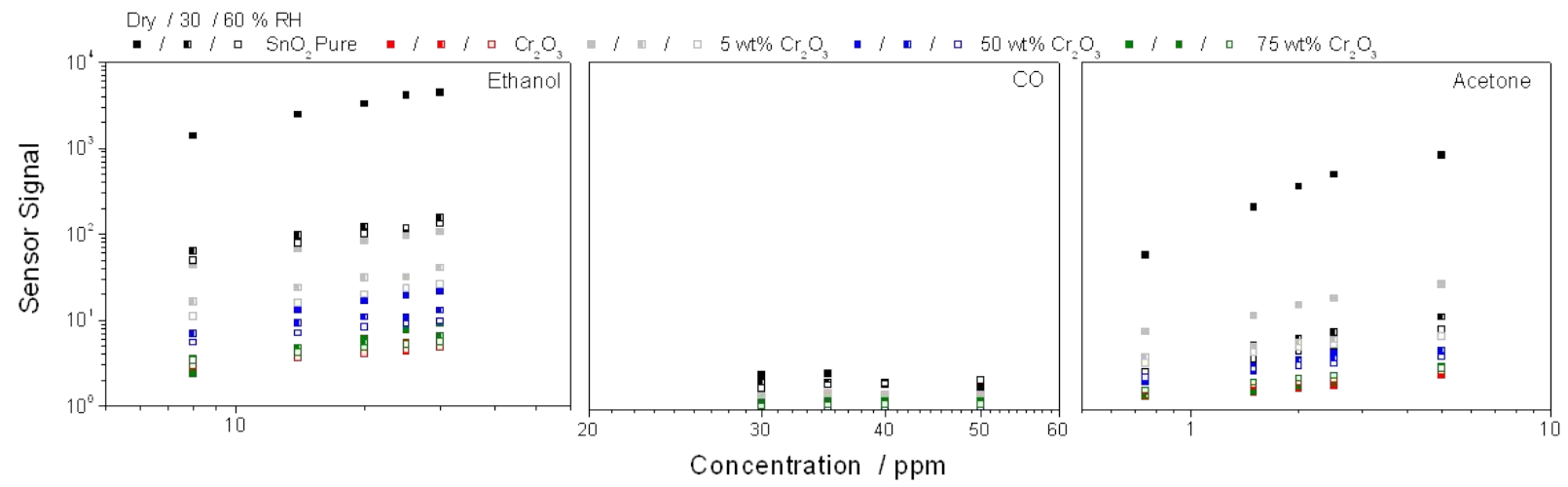

Figure S. 1: The calibration curves of all the sensors to the different gases.

*nb@ipc.uni-tuebingen.de 

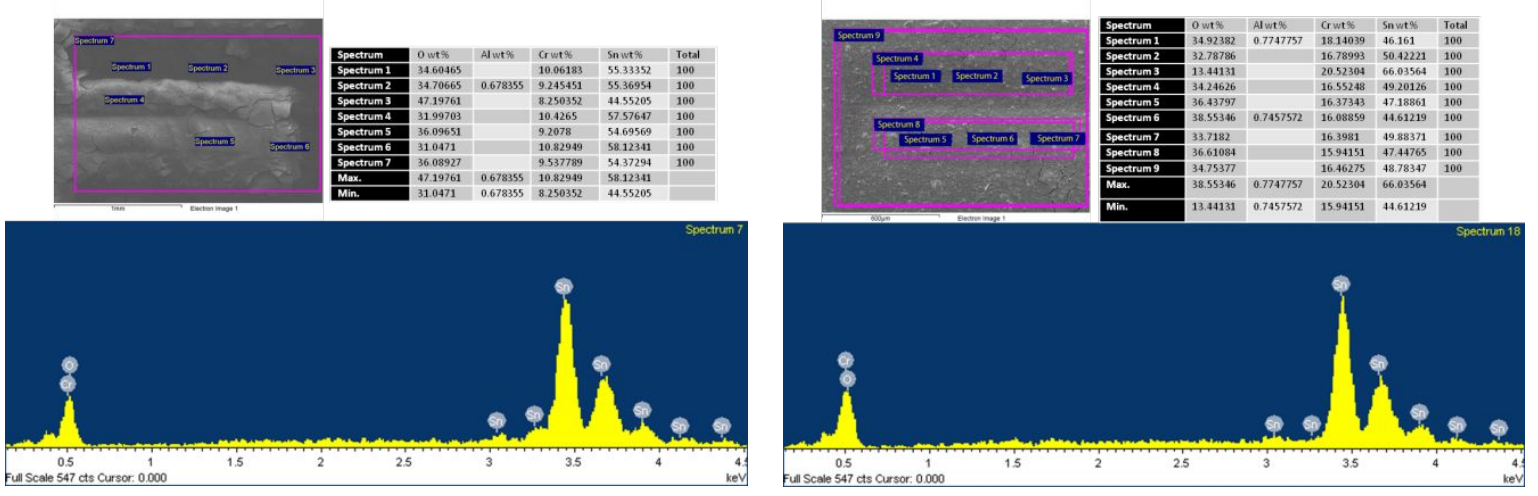

Figure S. 2: EDX of (Left) $\mathrm{Cr}_{2} \mathrm{O}_{3}-\mathrm{SnO}_{2}$ Core Shell crushed and (Right) $\mathrm{SnO}_{2}-\mathrm{Cr}_{2} \mathrm{O}_{3}$ core-shell crushed nanofibers.

(a)

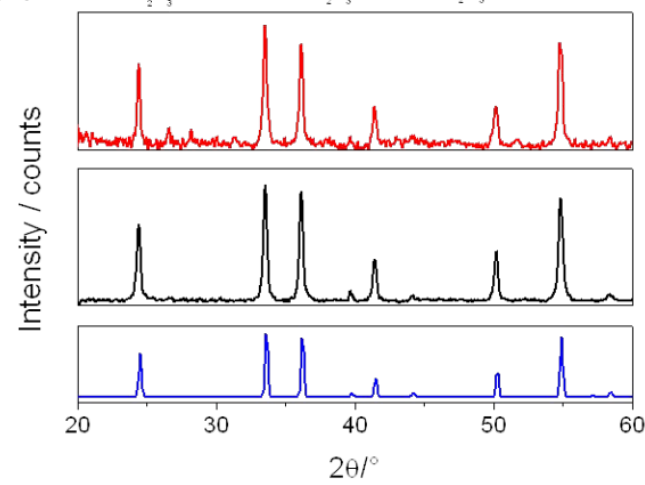

(b)

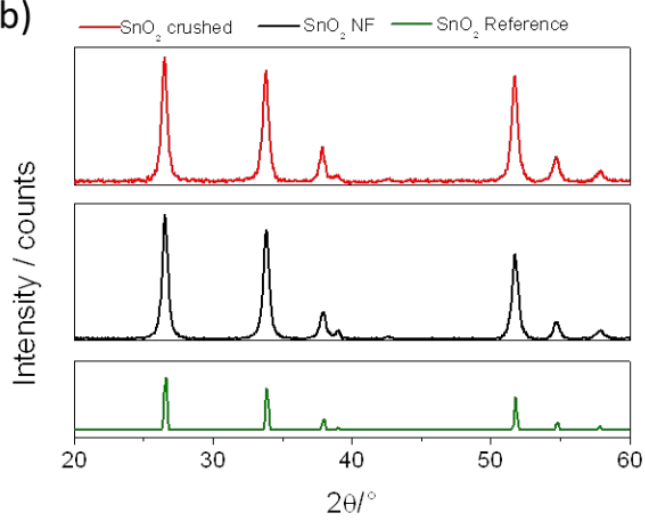

Figure S. 3: XRD spectra of (a) pure $\mathrm{Cr}_{2} \mathrm{O}_{3}$ nanofibers/crushed sample and a reference. (b) pure $\mathrm{SnO}_{2}$ nanofibers/crushed sample and a reference. The results for $\mathrm{Cr}_{2} \mathrm{O}_{3}$ were compared to reference data from Sawada at al. and for $\mathrm{SnO}_{2}$ to that of Baur et al. ${ }^{1,2}$ 


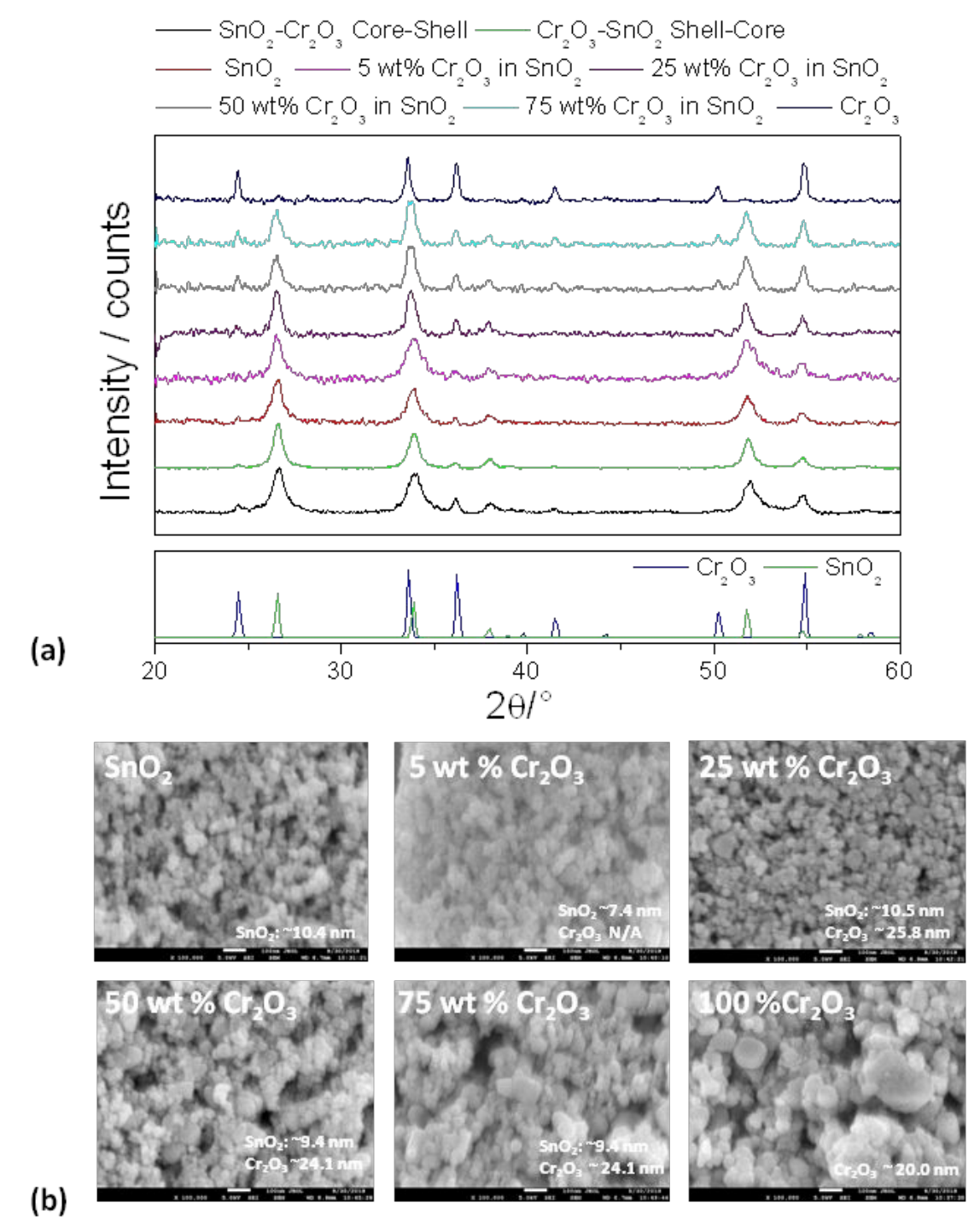

Figure S. 4: (a) SEM images of the sensors based on the crushed samples. (b) The XRD of the pure and composite materials. Using the Debye Scherrer equation the grain size of the different oxides was approximated (for $\mathrm{SnO}_{2}$ the reflex at $26.5^{\circ}$ was used and for $\mathrm{Cr}_{2} \mathrm{O}_{3}$ the reflex at $36.3^{\circ}$ was used). The results for $\mathrm{Cr}_{2} \mathrm{O}_{3}$ were compared to reference data from Sawada at al. and for $\mathrm{SnO}_{2}$ to that of Baur et al. ${ }^{1,2}$ 


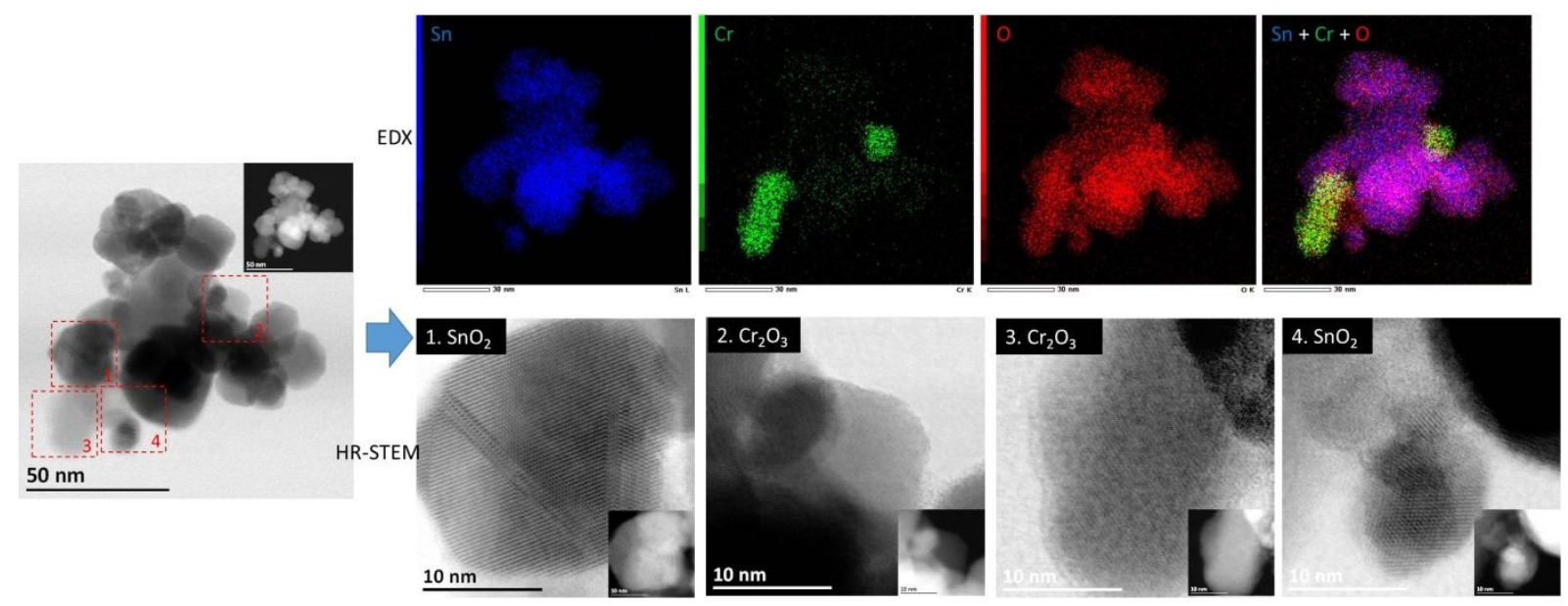

Figure S. 5: STEM images and EDS elemental mapping images of the $25 \% \mathrm{Cr}_{2} \mathrm{O}_{3}$ in $\mathrm{SnO}_{2}$. Additionally magnified images of different regions of the sample are shown.

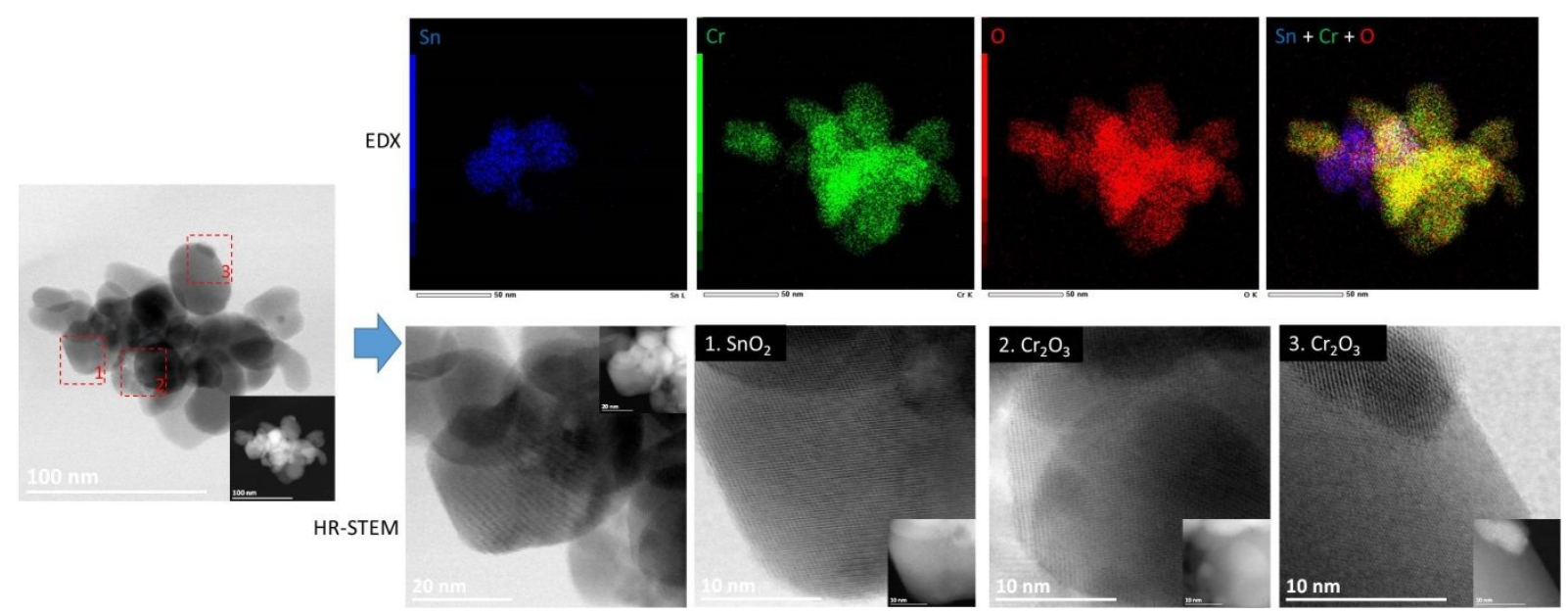

Figure S. 6: STEM images and EDS elemental mapping images of the $50 \% \mathrm{Cr}_{2} \mathrm{O}_{3}$ in $\mathrm{SnO}_{2}$. Additionally, magnified images of different regions of the sample are shown.

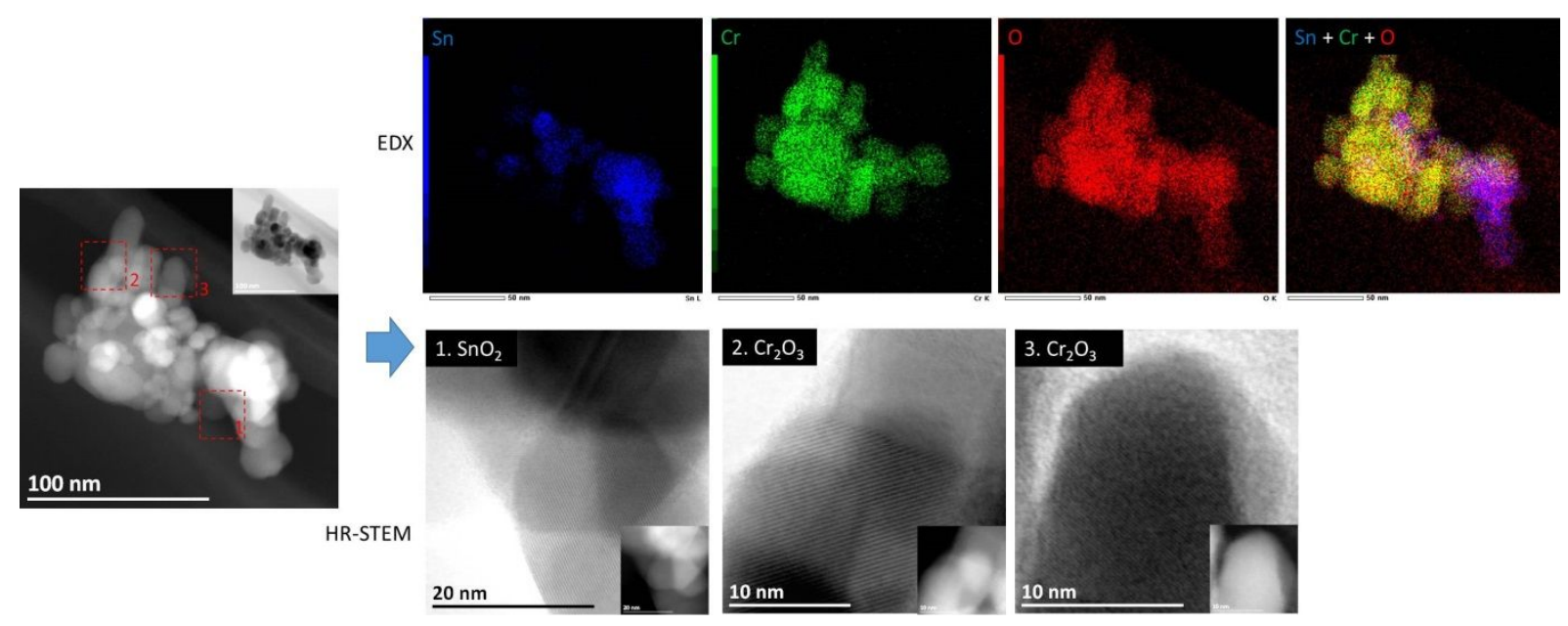

Figure S. 7: STEM images and EDS elemental mapping images of the $75 \% \mathrm{Cr}_{2} \mathrm{O}_{3}$ in $\mathrm{SnO}_{2}$. Additionally, magnified images of different regions of the sample are shown. 


\section{REFERENCES}

(1) Sawada, H. Residual Electron Density Study of Chromium Sesquioxide by Crystal Structure and Scattering Factor Refinement. Mater. Res. Bull. 1994, 29, 239-245.

https://doi.org/https://doi.org/10.1016/0025-5408(94)90019-1.

(2) Baur, W. H.; Khan, A. Rutile-Type Compounds. IV. $\mathrm{SiO}_{2}, \mathrm{GeO}_{2}$ and a Comparison with Other Rutile-Type Structures. Acta Cryst . B 1971, 27 (11), 2133-2139.

https://doi.org/10.1107/S0567740871005466. 